\title{
DIMENSION PSICO-SOCIOLOGICA DEL DEPORTISTA EN EL CONTEXTO DE LA VIDA MUNICIPAL (*)
}

796: 352

por

Julián Carrasco Belinchón

SUMARIO: I. INTRODUCCION.-II. PLANTEAMIENTO.-III. DIMENSION PSICOLOGICA DEL DEPORTISTA: 1. INGENIO. 2. INICIATIVA. 3. INTEGRIDAD. 4. ForTALEZA.-IV. DIMENSION SOCIOLOGICA DEL DEPORTISTA: 1. Autodisciplina. 2. Creatividad. 3. Factibilidad. 4. COOPERACIÓN.-V. CONCLUSION.

\section{INTRODUCCION}

El pasado año, por estas mismas fechas, tenía el honor de dirigirme en Fuengirola a los participantes en el III Seminario «Municipio y Deporte», exponiendo mi tesis sobre el deporte en la política municipal española. En aquella ocasión, a fuer de ser sincero, comenzaba declarando que era un auténtico amateur en el campo deportivo. Hoy, he de reconocer, con la misma sinceridad que entonces, que, como consecuencia de mi primera carrera en pista en Fuengirola, casi me he convertido en un verdadero profesional del

(*) Texto literal de la conferencia pronunciada en la clausura del IV Seminario «Municipio y Deporte», el 12 de mayo de 1978, en Palma de Mallorca. 
deporte, como lo acreditan mi participación como ponente en la Asamblea General del Deporte, mi responsabilidad como organizador y como director de las VI Jornadas del Programa de Participación Corporativa sobre el tema «El deporte en el ámbito municipal», celebradas en La Coruña en febrero pasado, y mi entrenamiento para competir en este IV Seminario. Todos estos hechos que he protagonizado son, sin duda, jalones deportivos $\mathrm{y}$, al mismo tiempo, galardones alcanzados de igual naturaleza.

Hoy, también, tengo la íntima satisfacción de dirigirme a los integrantes de este Seminario, merced a la benevolencia y a la amistad de José Payeras, al que agradezco sinceramente la nueva oportunidad que me ha brindado de estar con ustedes y de poder dirigirme a ustedes.

Si bien he de confesar que ahora, en el trance de tener que saltar con pértiga del tema del pasado año al del actual, me asalta el temor -que he de procurar dominar- de si sabré tener el ímpetu suficiente y el control de reflejos adecuados para superar con éxito la altura establecida en las deliberaciones de este Seminario.

Ante este dilema, no sé si lo más adecuado será actuar sobre patines para llegar al final rápidamente, y así cansarles menos; o tratar de mantener su atención sosegadamente, en cuyo caso quizá lo más conveniente sea seguir un ritmo pausado y uniforme, como el de los remeros en las competiciones fluviales.

De todos modos, mi verdadero deseo sería el que, al llegar a la meta, me pudiesen felicitar, si no como el triunfador $-\mathrm{mi}$ habitual optimismo no llega a tanto- al menos como un participante que había puesto a contribución lo mejor que posee: sus limitados conocimientos sobre el ser humano.

Conocimientos que se brindan, no con una pretensión magistral de enseñar, sino con el modesto propósito de servir. Teniendo en cuenta que la obra más bella del artista no es la que sale de sus habilidosas manos, sino la que alienta y fluye con sinceridad de su corazón. Y, en este caso, este ya veterano deportista -que creo, de verdad, que se debe retirar definitivamente con su intervención de hoy de estas lides- y aprendiz, por otra parte, de artista, brinda a todos sus sentimientos y va a ofrecer a todos sus pensamientos sobre el tema «Dimensión psico-sociológica del deportista en el contexto de la vida municipal». 
Disertación que, en definitiva, no va a ser, ni más ni menos, que aprovechar este marco de concentración de deportistas, para realizar conjuntamente un entrenamiento mental con espíritu deportivo y con ánimo competitivo, para formular una série de reflexiones y para plantear diversas directrices sobre el sentir, el pensar y el actuar del deportista. Reflexiones y directrices que desearía que fuesen, para unos, el punto de partida; para otros, el relevo en sus criterios $y$, para otros, en fin, la consagración de sus creencias

Ha llegado, pues, el momento de lanzarse desde el trampolín, para sumergirse en las tibias aguas del tema y procurar nadar con acierto entre las diversas cuestiones que el mismo entraña, afrontando cada una con impetu, pero también con medida, para evitar que lleguen ustedes agotados al final de la prueba.

\section{PLANTEAMIENTO}

Vamos, pues, a hablar del deportista, es decir, de la mujer o del hombre, que se dedica de una manera plena o de un modo parcial a la práctica de un deporte determinado. Pero el deportista ¿quién es? Es, en definitiva, una mujer o un hombre que siente, que piensa y que tiene una ilusión: alcanzar una meta. Pero ¿cuál es ésta?, ¿ser el mejor en su ámbito?, ¿ser el campeón en éste?, ¿el alcanzar un galardón? o ¿servir de modelo o de paradigma para los demás? Su motivación puede ser alguno de estos fines, o varios o todos a la vez. Pero esta mujer o este hombre se hallan inmersos en un mundo concreto que les circunda, que les condiciona y que igualmente les posibilita. Es el microcosmos de su familia, de su profesión, de sus amistades y de su pueblo o ciudad. Pero es que, además, esta mujer o este hombre han de actuar de acuerdo con unos parámetros, que son los principios que inspiran su conducta. Esto significa que el deportista; en cuanto ser social, se desenvuelve dentro de un marco de esta naturaleza, y que, como ser individual, está influenciado y determinado por componentes psíquicos, con lo cual resulta que su sentir, su pensar y su actuar es la resultante de factores sociológicos y psicológicos, que se muestran inseparables.

Este es, en definitiva, nuestro protagonista, que va a ser objeto de nuestra reflexión y de nuestra atención a lo largo de la diser- 
tación. A primera vista, parece que sería suficiente con describir sus características físicas, con mencionar las cotas por él alcanzadas, con reseñar las medallas conseguidas, con narrar las veces que subió al podio y con referir las ocasiones en las que, lamentablemente, su esfuerzo no fue coronado por el éxito. $\mathrm{O}$ ¿sería preciso, además, centrar la atención en la intensidad de los latidos de su corazón cuando compite?, o ¿fijar nuestra vista en sus frustraciones cuando no alcanza el éxito?, o ¿contemplar y valorar sus renunciaciones cotidianas para mantenerse en forma?

Creemos que es necesario e ineludible considerar globalmente todos los aspectos, poniendo todo énfasis en el espíritu y en el alma de esa mujer y de ese hombre, que con inteligencia, con voluntad y con entrega absoluta se trazan una meta a alcanzar.

Ahora bien, el deportista en su doble dimensión, ¿por qué va a ser objeto de nuestro estudio? Fundamentalmente, por una doble motivación: por una parte, porque el deportista es un vecino, es decir, miembro de una comunidad municipal, $y$, por otra parte, porque entendemos que las notas que caracterizan al deportista pueden ser también las que definen al político municipal.

A este respecto, podemos recordar que en nuestra disertación del año pasado examinamos, por un lado, lo que el Municipio debía hacer por el deporte y, por otro lado, lo que el deporte podría hacer por el Municipio. En la presente ocasión, volvemos a jugar con el mismo tema, si bien lanzando el balón desde corners distintos. En el partido, en el campo de Fuengirola, los equipos fueron el deporte y el Municipio; ahora, en el de Palma de Mallorca, son los deportistas y los políticos.

Como punto de partida, tomamos un acontecimiento ocurrido en el intervalo entre ambos partidos: el ingreso de España en el Consejo de Europa. Acontecimiento que determina que cada día se tenga que prestar más atención a las Recomendaciones y Acuerdos de este Organo, así como también a los de los que actúan en su entorno. En este sentido, entendemos que merece traerse aquí la Carta Europea del Deporte y los textos concordantes con la misma, en la parte que puede y debe condicionar e influir la actuación de los dirigentes municipales en el ámbito deportivo.

Del preámbulo de dicha Carta, merecen destacarse estas tres proposiciones: 
1. $\quad$ El deporte, al brindar actividades creadoras y ocupaciones recreativas, puede aportar diversas contribuciones al desarrollo personal y social.

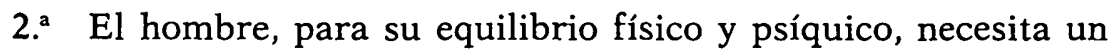
mínimo de ejercicio físico.

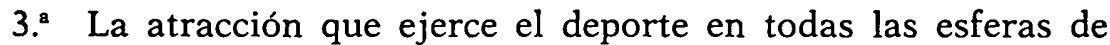
la población y su valor particular en un mundo que se transforma rápidamente y se caracteriza no sólo por un aumento del tiempo de ocio, sino también por una urbanización y un desarrollo tecnológico que tienden a disociar al hombre de su medio ambiente natural.

En su parte dispositiva consideramos igualmente trascendente su artículo III, al declarar que "siendo el deporte uno de los aspectos del desarrollo socio-cultural, debe ser tratado a nivel local, regional y nacional, conjuntamente con otros ámbitos donde intervienen decisiones de política general y una planificación: educación, salud pública, asuntos sociales, fomento de los recursos naturales, protección de la Naturaleza, artes y ocio».

Con posterioridad a la aprobación de dicha Carta, se acordó en 1975 otro texto complementario, relativo a la Función de los Poderes públicos en lo que se refiere al desarrollo del deporte para todos, del que merecen también destacarse las siguientes declaraciones:

1. ${ }^{\mathrm{a}}$ El deporte debe ser una parte integrante de los programas de desarrollo cultural, educativo, social y de salud.

2. Una política deportiva sólo puede ponerse en práctica y determinarse gracias a la cooperación de todas las entidades privadas y públicas relacionadas directa o indirectamente con el deporte, ya sea voluntario $\mathrm{u}$ obligatorio.

3..$^{a} \quad$ Desde el punto de vista de la educación permanente, deben establecerse relaciones más estrechas entre la educación física y deportiva escolar y el deporte voluntario.

4. ${ }^{\mathrm{a}}$ En la medida de lo posible, los poderes públicos deben fomentar la práctica del deporte:

- entre los trabajadores jóvenes y aprendices, lo mismo que entre los alumnos y los estudiantes; 
- entre todas aquellas personas que tengan obligaciones particulares en el ámbito profesional y familiar;

- entre los minusválidos, ya sean mentales o sociales;

- entre las personas de la tercera edad, y

- entre los emigrantes.

5. ${ }^{\text {a }}$ Deberán ponerse todos los medios para que el deporte no se convierta jamás en una ocasión de comportamiento excesivo, ni en un instrumento de propaganda política, ni en un factor de alienación individual y social, ni tampoco en un medio que aparte la atención de las poblaciones de los grandes problemas económicos y sociales.

En las declaraciones reseñadas, por una parte, se proclama y reconoce la responsabilidad municipal en el campo deportivo; y, por otra parte, se ratifican las afirmaciones que expusimos el pasado año, con lo que se establece una vinculación entre la tesis mantenida entonces y la que vamos a formular ahora, si bien, como hemos anticipado, la variación va a ser el cambio del objeto de atención: el deportista y los políticos municipales.

En consecuencia, nuestra disertación se va a dividir en dos tiempos con una prórroga.

En el primer tiempo estará en el campo la dimensión psicológica del deportista; en el segundo, lo ocupará la dimensión sociológica, y en la prórroga pasarán a él los políticos municipales para tirar los penalties y así decidir el resultado definitivo.

\section{DIMENSION PSICOLOGICA DEL DEPORTISTA}

Al hablar de dimensión psicológica nos referimos a la faceta individual del deportista. Es decir, contemplado en sí mismo, abstracción hecha del entorno en el que se desenvuelve. $Y$, desde esta perspectiva, creemos que las cuatro notas principales que requieren una atención prioritaria son: el ingenio, la iniciativa, la integridad y la fortaleza. Consideremos brevemente cada una de ellas: 


\section{INGENIO}

A. Pinilla nos dice que el ingenio «es la capacidad para encontrar soluciones inteligentes a los sucesivos problemas que se plantean al advenir situaciones nuevas. Es tener facultad de pensar con rapidez e inventar con facilidad". El ingenio se nos muestra, pues, como la aptitud para convertir en soluciones las cuestiones que nos presentan como problemas.

Ahora bien, hay que advertir que el ingenio no es necesariamente sinónimo de alta inteligencia, pues es suficiente con una inteligencia normal, pero, eso sí, activa. Es decir, puesta a contribución en todo instante y a máxima intensidad. Supone, en definitiva, actuar al máximo la capacidad que se posee y con la mayor prontitud. El ingenio, en el plano conceptual, lleva a la respuesta adecuada en el instante oportuno. El ingenio, en el plano de la realidad, conduce a la acción apropiada en el momento preciso.

El deportista, ¿precisa ingenio? Creemos que sí, y que, además, debe ser la primera nota psicológica que debe caracterizar su personalidad, pues sin ella de poco le servirían las cualidades físicas que posea. En cambio, con ella puede potenciar al máximo estas cualidades.

En efecto, hay que reconocer que el deportista con éxito es, precisamente, aquel que, merced a su ingenio, sabe utilizar al máximo sus condiciones físicas y aprovechar las circunstancias en las que las pone a contribución. La rapidez de reflejos, la constancia, el autodominio y otra serie de comportamientos análogos no son más que la consecuencia del ingenio aplicado en cada instante.

\section{INICIATIVA}

Consideramos a la iniciativa como la segunda nota característica del deportista, la que concebimos como la capacidad para saber marcarse sus propias metas, asi como también para establecer el ritmo de su consecución. Implica, pues, saber cuáles son las posibilidades que se tienen y el tiempo que se requiere para convertirlas en realidad.

La iniciativa supone ser consciente de las posibilidades que se tienen, en base a las aptitudes que se poseen y del esfuerzo que se 
está dispuesto a realizar para plasmarlas en la realidad. Entraña, por tanto, conocerse a sí mismo y valorarse con objetividad. Si lo primero es difícil, hay que reconocer que lo segundo lo es mucho más. En efecto, si se ha afirmado «el hombre, ese desconocido», se puede sostener que, para quien más, lo es precisamente para sí mismo; con lo cual, el valorarse, de ordinario, es empresa ardua, cuando no imposible.

En este sentido, nos encontramos, como posiciones límite: quienes se infravaloran y quienes se supervaloran. Aquéllos, por considerar que no poseen ninguna cualidad relevante $\mathrm{y}$, como consecuencia, que no son capaces de hacer nada meritorio. Se autocalifican como "del montón», y no acometen por su cuenta empresas, pues están convencidos de que fracasarán, por lo que el temor al ridículo les lleva a seguir a los demás y a hacer únicamente lo que a los demás se les ocurre. Y sólo cuando se ven forzados a iniciar alguna empresa, que coronan con el éxito, encuentran su oportunidad para el despegue autonómico posterior. Como, lamentablemente, no siempre ocurre esto, nos encontramos con que se derrochan grandes energías existentes, que quedan sin utilizar. A este respecto, cabe afirmar que la mayor parte de la capacidad humana queda habitualmente ignorada y sin aprovechar. Es una situación análoga a la de los grandes ríos que desembocan en el mar y cuyas aguas sólo sirven para purificar el ambiente y, a lo sumo, para que en ellas naden los patos u otros animales.

La otra postura extrema, como dijimos, la encarnan las personas que se supervaloran, $\mathrm{y}$, como consecuencia, se consideran capaces de hacer todo $y$, además, siempre bien. Supercapacidad que tiene su origen, en unos casos, en el nacimiento; en otros, en el patrimonio o en el matrimonio; y en otros, en fin, en la profesión. La capacidad originaria se presenta cuando el sujeto entiende que es propiamente un genio y que, por tanto, puede acometer cualquier empresa. Con lo cual, en ocasiones alcanza grandes éxitos que le encumbran aún más, pero que en otras fracasa estrepitosamente y queda después oculto tras el tupido velo del olvido. Hay que reconocer que es, de los tres grupos, el menos peligroso, si bien resulta molesto, a veces, por la soberbia con que se manifiesta y con que actúa.

La capacidad adquirida por vía material: patrimonio o matrimonio, eleva al sujeto a una actitud de superioridad que le lleva a creerse apto para acometer empresas desde la altura en que le han 
situado los recursos económicos que disfruta. Empresas que frecuentemente no corona con acierto, salvo que, además de recursos, tenga algo de inteligencia. Las personas de este tipo, a menudo, suelen ser peligrosas, pues las coordinadas de su actuación son el orgullo en ellas y el desprecio hacia los demás.

La capacidad basada en la profesión se da en aquellos casos en los que, a través de distintas vías y mediante procedimientos más o menos lícitos, se culmina en ciertas profesionès, muy cualificadas y singularizadas, en las que sus titulares se consideran, por el simple hecho de haberlas conseguido, investidos de un poder omnímodo ante el que los demás han de someterse servilmente. En estos casos, la investidura transforma al sujeto en un ser sabedor de todo, hecho casi a imagen y semejanza del Sumo Creador, ipero sin su sabiduría divina ni con su bondad infinita! Los investidos de este poder, hacen y deshacen a su capricho y sin límite, ignorando la dignidad de los demás, que son en sus manos simples instrumentos ejecutores de sus demenciales ideas, que al plasmar en la realidad son un fracaso continuo. El que, de ordinario, se imputa a la incapacidad de los ejecutores, los que, de esta forma, son doblemente víctimas de tales individuos: al soportarlos cotidianamente y al sufrir su inquina frecuente ante el estropicio causado por su encubierta incapacidad. Las personas pertenecientes a este grupo son las más nefastas.

Entre ambos extremos se encuentra la persona, mujer $u$ hombre, que teniendo una idea cabal de sus posibilidades, es modesto al valorarlas, pero tenaz al ejercitarlas; con lo cual, de ordinario, logra las metas que se ha propuesto. Metas que son realistas y por tanto alcanzables, en base a sus condiciones personales y a sus cualidades profesionales, que las adiestra al máximo y que las pone a contribución con oportunidad y también con firmeza.

$\mathrm{Si}$, por último, estas ideas generales las trasladamos al campo deportivo, hemos de reconocer que tienen una plena virtualidad, por cuanto en este ámbito nos encontramos con frecuencia con el deportista:

- que no logra el éxito, por no confiar en sí mismo, y que queda oculto tras la nebulosa del olvido;

- que fracasa por pretender cotas que no puede alcanzar, y que luego se le recuerda como paradigma de fatuo, de engreído y de necio, y 
- triunfador, que optimizó sus posibilidades y que maximizó sus oportunidades, al que acompaña el palmarés del éxito, que le alienta para nuevas empresas.

\section{INTEGRIDAD}

Como tercera nota consideramos a la integridad, entendida con A. Pinilla como «una conducta que signifique en todo momento la realización y defensa de los más altos valores, que entrañe un ejemplo a imitar por los demás». La integridad, así concebida, supone, por un lado, un comportamiento delineado y condicionado en todo instante por un sistema de valores de componente ético, y por otro lado implica asumir una conducta modélica para los demás, pero no porque la califique así su propio sujeto, sino porque de hecho le reconozcan tal carácter los restantes.

- Podemos, pues, afirmar que la integridad se nos muestra como un ideal y al mismo tiempo como una realidad. Aquél inspira el comportamiento y ésta lo plasma en la actuación cotidiana del sujeto. Al hablar de ideal estamos intencionadamente poniendo de relieve lo difícil que es de seguir por el ser humano, atormentado por sus aspiraciones y por sus debilidades y aprisionado por sus intereses y por sus prejuicios. Fuerzas antagónicas que luchan por alcanzar objetivos opuestos: altruismo o egoísmo; generosidad o tacañería, sentido social o espíritu individualista. Esta es la tragedia cotidiana de la mujer y del hombre que se hallan sometidos a la carga y a la presión de estos factores, y que determinan que en unas ocasiones se nos presenten como el Dr. Jekyll, y en otras oportunidades aparezcan como $M r$. Hyde, siendo, no obstante, siempre los mismos, pero distintos en cada instante.

El predominio de unos u otros factores determinan que se pueda hablar de integridad o que se tenga que reconocer que se carece de ella. Si bien hay que advertir que si en un plano puramente teórico resulta fácil de deslindar uno y otro caso, y calificar, como consecuencia, de íntegro al que se nos muestra como un compendio de ciertas perfecciones, y como no íntegro al que carece por completo de las mismas. En cambio, en el mundo fáctico y referido en concreto a cada sujeto singular, la cosa ya no es tan sencilla, al menos en el terreno de la valoración de las conductas. Por cuanto, sin tener que acudir al trascendente Mensaje Evangélico de «no 
juzguéis si no queréis ser juzgados», hay que reconocer que objetivamente sólo se pueden emitị juicios cuando se cuentan con los suficientes elementos de conocimiento. Los que de ordinario se carece, pues éstos pertenecen a la intimidad del sujeto y, por tanto, no es sencillo detectarlos y menos valorarlos.

En consecuencia, ¿significa esto que la integridad es una pura entelequia? Entendemos que no, y por ello la definimos como una de las notas que debe caracterizar a toda mujer y a todo hombre, y en especial a quienes sean deportistas. Entraña que en el aspecto de ideal de conducta - que hemos indicado- ha de ser primordialmente la resultante de una reflexión del propio sujeto. El que ha de ser consciente de que para ser respetado por los demás, primero se ha de respetar a sí mismo. Respeto que implica acomodar su comportamiento personal a unos principios éticos — de significado religioso o no, según sus propias creencias- que están por encima de su libertad individual, la que, por otra parte, es factible en el grado en que se ejercite conforme a tales principios, que son, precisamente, el marco que delimita y posibilita dicha libertad. La que, en otro caso, carece de virtualidad y se convierte, paradójicamente, en cadena de esclavitud, en vez de ser eslabón para el ejercicio del libre albedrío.

Si ahora, por último, pasamos de lo genérico a lo específico, es decir, a lo deportivo, ¿qué significa la integridad para la mujer o para el hombre deportista? Supone, por un lado, un gravamen, y por otro, un podio. El gravamen, en cuanto su conducta se ha de supeditar y se ha de conformar a unos patrones, en los que no tienen acomodo ni las malas artes, ni las tretas, ni el engaño, y en cambio en los que han de brillar la honestidad, la objetividad y la franqueza. Es un podio, por cuanto el deportista ha de irradiar limpieza en el espíritu, ha de desplegar generosidad en su actuación y ha de contagiar a los demás solidaridad.

El deportista, en definitiva, ha de ser el que más ha de dar, entregándose a la empresa que realiza, sin buscar o pretender prebendas: Su recompensa se halla no en el premio que recibe, sino en la meta que logra; no en el reconocimiento que consigue, sino en las cotas alcanzadas. Su triunfo se encuentra en la concordancia entre el esfuerzo que realiza y en las marcas establecidas. $\mathrm{Y}$ todo ello, en fin, no como un mérito individual, sino como un logro colectivo. 


\section{Fortaleza}

La última nota característica de este tipo que queremos glosar es la fortaleza, entendida como la capacidad para resistir las adversidades y para verificar los esfuerzos que sean precisos para hacer frente a las circunstancias de cada momento y superarlas con acierto $y$ con éxito. Esto significa que la fortaleza tiene una significación bifronte: defensiva y ofensiva.

Desde el punto de vista defensivo, la fortaleza supone la habilidad para encajar golpes, sean físicos o sean psíquicos, teniendo en cuenta que estos últimos requieren más aptitud de recuperación que aquéllos, pues en los golpes físicos se consigue más fácilmente y con mayor prontitud la reanimación y la normalidad. En cambio, los golpes psíquicos producen heridas de no fácil suturación y de lenta cicatrización, que dejan huella que el tiempo difícilmente hace desaparecer.

En este sentido, pensemos, por ejemplo en las heridas a la dignidad de la persona, en las que su cierre - si se llega a producires lento, dejando en tal supuesto señal indeleble. Herida que con frecuencia se vuelve a abrir, y aún con mayor profundidad, si se repite la agresión por parte de quienes, por entender que gozan de situaciones de fuerza o por estimar que disfrutan de posiciones de poder, lastiman aquélla, por considerar que tales situaciones o posiciones les permiten jugar irresponsablemente con los sentimientos de la persona, a la que relegan a la condición de un mero juguete en sus manos todopoderosas.

La fortaleza, pues, en este primer sentido, se nos muestra, por tanto, como sinónima de abnegación y de paciencia. Si bien ambas, no hemos de olvidarlo, tienen sus límites. De tal forma que zabe afirmar que cuanta más elasticidad tengan la mujer o el humbre para soportar la adversidad y para aguantar la presión, mayor puede ser la reacción de una y de otro cuando llegan al límite de la misma. Es decir, que el que se muestra más paciente puede después llegar a ser el más violento, al superar el límite de aguante y volcar toda la carga retenida.

A este respecto, hay que tener presente que si la persona llega a una situación límite, en la que la tensión a que se la somete la lleva al convencimiento de que se la pretende aplastar y siente al mismo tiempo una aguda sensación de impotencia, su respuesta 
puede ser, hoy o mañana - según se lo permitan las circunstancias-, de alcance imprevisible y de consecuencias incalculables.

Desde el punto de vista ofensivo, la fortaleza significa, por otra parte, la aptitud para realizar cuantos esfuerzos sean precisos para alcanzar los objetivos pretendidos. Desde esta perspectiva, la fortaleza ha de contemplarse, a su vez, desde la vertiente psicológica y desde el prisma físico, pues ambos se presentan íntimamente ensamblados; de tal forma que si se disocian, carecen de operatividad una y otro. En efecto, la fortaleza entraña, en primer término, un raciocinio de lo que se quiere, así como también de lo que se puede alcanzar; pero, además, la acción de la razón debe estar presente en todo instante cuando se pasa a la actuación, para acentuar la voluntad, para controlarla e incluso para anularla en ciertos períodos, en los que entra en juego la inercia: el dejarse llevar. En definitiva, la fortaleza se nos muestra como un acto volitivo, antes, en y después de la acción, que sólo tiene significado si siempre responde a una preocupación racional, que es lo que precisamente diferencia al hombre de los restantes seres vivos.

La fortaleza implica, en segundo lugar, el ejercicio de las cualidades físicas del sujeto, potenciándolas al máximo y poniéndolas en tensión en el momento oportuno y en el instante preciso. Potenciación y tensión son los factores concurrentes que hacen a la mujer o al hombre descollar y brillar con luz propia, tanto al acometer empresas importantes, como al afrontar adversidades, como al superar dificultades y como al vencer obstáculos. La fortaleza en este sentido se identifica con la resistencia física, que depende no tanto de las cualidades de este tipo que posee el sujeto, como del grado en que inteligentemente sepa aprovecharlas; lo que implica tanto un adiestramiento oportuno como un empleo apropiado. En este sentido, cabe sostener que no es más fuerte el que posee más fuerza, sino el que sabe utilizarla convenientemente, y aquí tiene un lugar trascendente el entrenamiento.

El papel que la fortaleza juega en la vidá del deportista es tan evidente y es tan relevante, que quizá no fuese preciso ningún comentario específico. No obstante, queremos destacar brevemente la incidencia de los dos aspectos expuestos en la dinámica de la mujer y del hombre que practican cualquier deporte.

El aspecto defensivo supone su capacidad para encajar la derrota con buen talante y casi sin pestañear. Entraña tener el suficiente coraje para continuar la actuación como si nada hubiese 
pasado, y como si el otoño no hubiese marchitado el vergel de sus ilusiones; las que, pese a todo, permanecen frescas y lozanas, merced al rocío de su indómita voluntad, que las vivifica y las hace brotar aún con más pujanza cara a la primavera que se anuncia y que se atisba en el próximo horizonte y en el cercano amanecer. Una primavera que crea y que conforma el deportista con su ánimo firme y con su voluntad serena; que salen robustecidos después de la derrota. La que le sirve como acicate y como estímulo para el triunfo futuro, que se asentará en las nuevas bases que surgen de la experiencia obtenida en la derrota sufrida.

En este sentido, para el deportista la derrota padecida debe tener un triple significado: debe ser una enseñanza, tiene que ser una ocasión de reflexión y ha de ser una cura de modestia. En efecto, la derrota debe servirle de enseñanza, para descubrir los fallos imputables a sí mismo o a la organización; tiene que ser una ocasión de reflexión para hallar la fórmula idónea para volver a acometer la empresa sin caer nuevamente en los mismos errores, y ha de ser una cura de modestia, para erradicar cuantos atisbos de soberbia suscita insensiblemente el éxito. En definitiva, la derrota, así concebida, como mero accidente en la vida del deportista, puede ser saludable e incluso conveniente, pues es oportunidad para hacer que se reencuentre a sí mismo y es ocasión para que vuelva a poner los pies sobre la tierra.

El aspecto ofensivo, su capacidad de esfuerzo y de entrega, es de ordinario el más destacado y el analizado con más detalle: la puesta a punto, merced al entrenamiento; la tensión en las competiciones y las renunciaciones y las restricciones en el régimen de vida requerido para la potenciación de las cualidades físicas. Pero ahora nosotros sólo queremos poner de relieve una faceta que entra de lleno en otra nota que expondremos en el segundo tiempo del partido: esa capacidad de esfuerzo y de entrega entrañan, fundamentalmente, un autodominio que es, en definitiva, el que nos da la verdadera talla humana del deportista, independientemente de las cotas que alcance y de las marcas que establezca.

El deporte, en efecto, es para estas mujeres y para estos hombres la ocasión para proyectar su grandeza al haber sabido dominarse a sí mismos, que es, paradójicamente, de las empresas más arduas y difíciles que acomete el ser humano. El que siendo capaz de someter mediante la inteligencia o a través de la fuerza a los demás, es de ordinario incapaz de supeditarse a sí mismo a un 
orden. Supeditación que hay que advertir que no es castración, como se pudiese pensar, sino al contrario, alcanzar una potencia superior a la normal. Quien sabe dominarse es verdaderamente libre, mientras que el que está sometido a sus instintos y se encuentra dominado por sus caprichos, es un mero esclavo de sus debilidades, es un paje y bufón de sus devaneos y es, en fin, un auténtico siervo de su egoísmo.

\section{DIMENSION SOCIOLOGICA DEL DEPORTISTA}

Una vez contemplada la perspectiva individual del deportista en el primer tiempo del partido que acaba de concluir, vamos sin descanso intermedio, aprovechando la fortaleza de ustedes, a examinar en el segundo la otra vertiente: la sociológica. Lo que es tanto como analizar la personalidad de aquél desde el prisma del conjunto del que forma parte y por el que se halla en todo instante condicionado, y. al que él, a su vez, influye y predetermina. En esta faceta son igualmente cuatro las notas que vamos a glosar y a sacar al campo: autodisciplina, creatividad, factibilidad y cooperación.

En nuestra propia tesis pensamos que estas notas, junto a las cuatro expuestas anteriormente, definen y caracterizan psico-sociológicamente al deportista. Ese ser, que decíamos concebíamos primordialmente como dotado de un espíritu y de un alma, aparte de contar con unas aptitudes físicas relevantes que le llevan a practicar con éxito un deporte determinado.

\section{Autodisciplina}

Para esbozar a grandes trazos lo que es y lo que implica la autodisciplina, tenemos nuevamente que acudir al pensamiento del ilustre Rector de la Universidad de Lima, A. Pinilla, quien nos dice: "ser disciplinado significa creer y practicar que la conducta reactiva y espontánea, por razones de bienestar común, debe ser orientada por una dirección inteligente fundada en un orden racional coherente y en un orden de valores auténticos». Añadiendo que los criterios que rigen la conducta humana de las personas disciplinadas, unos son racionales y otros son éticos. Entre los primeros menciona: veracidad, concordancia con los hechos de la ciencia y 
la lógica; eficiencia, economía de tiempo y de fuerza; más inteligente uso de los recursos humanos, financieros y técnicos; justicia distributiva y conmutativa; premio al mérito y satisfacción de las necesidades primordiales.

Entre los segundos cita: respeto mutuo, trato digno, cooperación y ayuda recíproca, generosidad y nobleza, dignidad, lealtad y consecuencia en la vida de relación social.

"Caracteriza la conducta disciplinada -concluye- el orden racional y axiológico que trasunta, lo cual no debe ser contradictoria, sino afirmativa de la autodeterminación individual».

La autodisciplina se nos muestra, pues, como la espontánea aceptación y el libre cumplimiento de las normas sociales que rigen la convivencia humana. Las normas se aceptan porque se consideran necesarias y se cumplen porque se estima que son indispensables para la armonía social. Aceptación y cumplimiento que no coartan la libertad individual, sino que, al contrario, la hacen factible en el marco de la comunidad en la que se vive y en la que se actúa.

Autodisciplina que por otra parte, como anticipamos, denota en el sujeto una superioridad, al no estar sometido a las propias veleidades, ni estar supeditado a las influencias interesadas de los demás. Quienes bajo pretexto de libertad y con etiqueta de progresismo pretenden taimadamente subordinarnos a sus particulares caprichos, convirtiéndonos en juguetes en sus manos y en esclavos de sus apetencias, en tanto les seamos útiles a sus enmascarados apetitos. Los que así se presentan y con frecuencia triunfan - salvo que se encaren con mujeres o con hombres autodisciplinados- son quienes, adornados con máscaras de sentimentales y con lamentos de incomprendidos, juegan fría e insensiblemente con los sentimientos de sus víctimas, y no comprenden - porque ni les interesa ni les preocupa- el daño irreparable que les hacen, pues lo único que buscan es su fácil éxito hoy, y mañana el exhibirlo como trofeo conquistado, merced a sus argucias y al engaño al que condujeron a quienes les creyeron con ingenuidad infantil, independientemente de la edad que tuviesen y de lo experimentados que se considerasen.

Si pasamos ahora a considerar el significado de la autodisciplina en el deportista, es manifiesto y es evidente que esta nota es unánimemente reconocida en el verdadero deportista. Por cuanto de ordinario, de una manera espontánea, acepta las reglas del juego y sus exigencias $\mathrm{y}$ de un modo libre las cumple. De tal forma que si 
hubiese que limitar a una sola característica definitoria del deportista, se elegiria precisamente ésta, y así cuando le falla decimos que no es un auténtico deportista.

En consecuencia, le es de aplicación el planteamiento general expuesto, así como sus matizaciones. En especial, los cantos de sirena, para que deje de ser libre y se convierta en siervo de quienes desean explotarlo bajo protesta de liberación y al son de alegatos de realización personal. El deportista en especial, como la persona en general, es de verdad libre cuando puede actuar conforme a sus principios y a sus propias creencias; no cuando inconscientemente se encuentra atrapado en la tela de araña del engaño primero y del chantaje después. ¡Cuántos deportistas han frustrado su carrera por caer en la trampa de quienes les quisieron perder! Y ¡cuántos deportistas destrozaron su existencia por una ilusión pasajera presentada oportunamente, en un momento en el que sufrían desánimo!

\section{Creatividad}

Como segunda nota de este tipo que caracteriza al deportista consideramos la creatividad, lo que, de acuerdo con M. R. FeINBERG, "es realmente sólo una variación de la manera de resolver un problema. Es poco más que un ejercicio para hacer frente a un desafío mental». Es, pues, la capacidad para hallar una manera original para resolver una cuestión, tanto inventando un nuevo procedimiento, como empleando un procedimiento preexistente para una finalidad distinta.

La creatividad no es más que la consecuencia del ejercicio del ingenio, puesto a contribución, tanto aprovechando los moldes ya existentes, como rompiendo éstos y sustituyéndoles por otros nuevos. La creatividad, en síntesis, entraña:

1. Un disconformismo con lo existente, que se considera inadecuado para dar respuesta a las necesidades presentes.

2:e. Un propósito de sustituirlo por otra cosa, que entiende que debe ser apropiada a las exigencias que ha de satisfacer.

3. Un ánimo por esforzarse en la búsqueda de la solución de recambio, sin parar en los sacrificios y trabajos que suponga. 
4. Una voluntad sincera para examinar con objetividad si la solución hallada es mejor que la preexistente, para en otro caso no sustituirla hasta que se haya encontrado otra más adecuada.

La creatividad, proyección de la capacidad imaginativa del ser humano, es el auténtico motor del cambio y del progreso, que encuentra, no obstante, obstáculos de todo tipo para desarrollarse. Entre otros, podemos mencionar a la indolencia y a la rutina, que invitan a mantener las cosas tal_como están. También se oponen la desconfianza y la envidia de los demás, como valladar a toda creación. En este sentido, cabe recordar el pensamiento de Moliére: «Si haces, serás criticado; si no haces, simplemente ignorado; pero si haces mal, a menudo serás premiado".

La creatividad, por último, supone en el deportista no tanto su habilidad para encontrar nuevas rutas que le lleven triunfalmente al podio - al que en muchas ocasiones le conducen-, cuanto su aptitud para diseñar nuevos modos de comportarse y de actuar dentro de un régimen de autodisciplina. El deportista creador se convierte así en el artista del deporte, que implanta y practica nuevas pautas, que después permanecen cuando él ya ha abandonado dichas prácticas.

En este sentido, si contemplamos retrospectivamente los distintos deportes, se puede observar que si bien ya no suenan los ecos de la música en honor de singulares vencedores, sin embargo sí permanece iluminado con luz propia la obra de aquellas mujeres o de aquellos hombres que con imaginación marcaron hitos de transformación en las prácticas deportivas. De tal forma que su creación cerró una página y abrió otra nueva en la historia del respectivo deporte. Esta perenne huella ha quedado a través del tiempo; en cambio éste ha arrumbado en el desván del olvido las distintas medallas conseguidas por los diferentes triunfadores. De tal modo que podríamos concluir afirmando que en el deporte, como en la vida, lo importante no es triunfar episódicamente; lo trascendente es crear, pero crear con realismo para mejorar lo existente. 


\section{-3. FACTIBILIDAD}

La tercera nota característica del deportista, que está estrechamente ligada a la de iniciativa, es la de factibilidad, que como nos dice A. Pinilla, implica «no emprender lo que no puede conseguirse. Es decir, no pretender lo que no puede lograrse. Supone encontrar el justo término entre lo posible, lo probable y lo deseable. Hallar, pues, un equilibrio entre lo deseable y. lo posible antes de acometer cuaquier empresa».

"Consiste - añade- en saber cuáles son las circunstancias favorables y en saber aprovecharlas; en conocer cuáles son los puntos fuertes y los puntos débiles de los propios planes y de los planes y de las acciones contrarias; en procurar que, al planear las circunstancias de la lucha competitiva, todo lleve al fortalecimiento de los propios puntos fuertes y al agravamiento de los puntos débiles del oponente».

«La acción - concluye - ha de caracterizarse porque quien la realiza actúa sabiendo y sabe actuar».

«Actuar sabiendo es ser lo suficientemente sensato como para no decidîsin poseer los conocimientos y la información adecuada. El tráfago de la acción cotidiana es tan dinámico, absorbente, cambiante y estimulante, que muchas veces prevalecen en la acción las reacciones emotivas, sentimentales o intuitivas. Se actúa habitualmente guiado más por el sentimiento y las emociones, tristeza o alegría, ánimo agresivo o cooperativo, que nunca debe ser el elemento rector de las reacciones y de la conducta de la persona".

«Hacer sabiendo quiere decir actuar de acuerdo a normas y principios y no de acuerdo a caprichos, emociones pasajeras o estados afectivos o tendencias instintivas, anímicamente condicionadas por circunstancias específicas. El nepotismo y la tiranía son formas de conducta mucho más corrientes de lo que se cree. El comportamiento sereno, equilibrado y racional que obedece a ideas y a principios es propio de la persona centrada, pero es algo difícil de encontrar. Hacer sabiendo es, ante todo, actuar, tomar decisiones, comprometerse en el curso de los acontecimientos, originando cambios que han de ser inteligentemente anticipados y evaluados. Las presiones no deben ser razón de causa para que la persona dirija su acción conforme a ellas». 
En el pensamiento de A. Pinilla, ampliamente reproducido, se contiene, en nuestra opinión, un planteamiento integral del significado de la factibilidad que creemos que merece reflexión. Por cuanto una de las características más típicamente españolas es precisamente el ignorar esta nota, tanto a título individual como en su ámbito social. Por ello entendemos que hay que prestarle especial atención, para procurar que en la actuación individual como en las empresas colectivas se tenga siempre presente y se puedan, como consecuencia, alcanzar resultados satisfactorios.

En definitiva, la factibilidad significa que la conducta humana ha de conformarse a un esquema integrado por las respuestas a los cuatro interrogantes siguientes: ¿qué?, ¿cómo?, ¿cuánto? y ¿cuándo?

- ¿Qué?: acometer únicamente lo que sea posible en cada momento.

- ¿Cómo?: actuar racionalmente, de forma creativa y de acuerdo con normas y principios.

- ¿Cuánto?: utilizar al máximo nuestras posibilidades.

- ¿Cuándo?: aprovechar las circunstancias favorables.

Estas cuatro respuestas delimitan el marco de una acción que debe ser positiva y que debe conducir a resultados altamente satisfactorios, tanto para la persona en general como para el deportista en particular. En efecto, entendemos que la mujer o el hombre deportistas sólo deben participar en aquellas competiciones en las que puedan realizar un papel decoroso. En ellas, aunque la pasión sea el motor, la razón debe ser el volante que conduzca y guíe en forma conveniente y apropiada por la pista, al máximo de velocidad que permita ésta y que pueda nuestro vehículo, es decir, nuestro organismo psíquico y físico.

\section{COOPERACIÓN}

Como última nota característica de este tipo consideramos a la cooperación, entendida como el espiritu de solidaridad, tanto concebido como identificación con los propósitos, como compenetración con los estuerzos de los demás, que da lugar a la aparición y exis- 
tencia del llamado espiritu de equipo. El que si es ineludible en el marco deportivo, se va haciendo cada día más necesario en el ámbito social, a medida que la dinámica de la sociedad actual se complica y se hace más exigente con sus miembros, que se encuentran cada vez más aprisionados por sus exigencias y por sus demandas crecientes. Urgencias y demandas que los atosigan y que los aplastan con el progreso tecnológico que conduce a una paulatina y acusada deshumanización, que desarraiga al hombre de su marco natural, en el que era "Rey y Señor», y que le está convirtiendo en una simple pieza más de la sofisticada tecnoestructura que padece la humanidad presente.

En este sentido, es válido el penšamiento de PARKER, cuando afirma que «entre los deseos más vitales de toda persona tenemos el de ser necesaria, un afán básico de ser importante y útil a los demás y de hacer una aportación personal al trabajo que resulte valiosa". Este deseo de interactuar y de servir a los demás es el fundamento de la cooperación, que para tener virtualidad ha de tener una base bilateral:

- ayudar y ser ayudado;

- servir y ser servido;

- preocuparse por los problemas de los otros y que éstos se preocupen por los nuestros, y

- sincronizarse con los demás y que ellos se sincronicen con nosotros.

En definitiva, la cooperación entraña sustituir al yo, al tú y al él, por el nosotros. Es decir, sentir, pensar y actuar al unísono, sin menoscabo de la individualidad de cada uno, que se ve reafirmada y reforzada en el grado en el que se intensifica dicho unísono en el sentir, en el pensar y en el actuar; con lo cual sucede que las personalidades individualizadas devienen en el equipo integrado.

Equipo que, repetimos, cada día es más necesario en el ámbito social y se nos muestra más imprescindible en el campo deportivo. Incluso en aquellas prácticas más individualizadas, en las que se requiere, como mínimo, la compenetración con el entrenador o instructor y con quienes realizan los trabajos auxiliares que posibilitan dicha práctica.

Podemos concluir, pues, afirmando que la cooperación es la base de la actividad deportiva y su condicionante primordial; de tal for- 
ma que sin ella difícilmente se puede practicar, y además es casi imposible obtener el éxito. Por cuanto si la unión hace la fuerza, la unión lleva al triunfo, o al menos potencia las posibilidades individuales del grupo, que se transforma así en un conjunto integrado que suma afanes y que multiplica esfuerzos.

\section{CONCLUSION}

$\mathrm{Y}$ hemos llegado al final del partido, en el que el protagonista ha sido la mujer y el hombre deportista, y ahora en la prórroga, que va a ser breve, salta al campo el político municipal. En efecto, creemos que en las ocho características examinadas se compendia un prontuario de actuación del político municipal, cualquiera que sea la ideología a la que pertenezca y del grupo social y profesional del que forme parte.

De tal modo que entendemos que el desempeño de su papel de dirigente de la política municipal se vería extraordinariamente facilitado si las polares de su singladura pública fuesen precisamente esas ocho notas analizadas. En consecuencia, propugnamos, para concluir, que lo deseable sería que los Alcaldes y los Concejales pudiesen caracterizarse, al igual que los deportistas, por las siguientes notas:

I. Ingenio, para saber hallar en cada momento las soluciones más idóneas a los cada día más complejos problemas que aquejan a las comunidades vecinales.

II. Iniciativa, para saber elegir, dentro de los problemas existentes, aquellos que requieren una satisfacción prioritaria, adecuando todo el esfuerzo a resolverlos, y no fraccionando éste en la pretensión de tratar simultáneamente distintos problemas.

III. Integridad, entendida tanto como el respeto y cumplimiento de los valores éticos en su actuación, como en el lograr que ésta pueda servir de ejemplo para los servidores municipales y para el pueblo en 'general.

IV. Fortaleza, concebida en el doble sentido de capacidad para hacer frente a las dificultades que les surjan en su gestión pública, así como también para saber soportar las frecuentes ingratitudes 
populares, y de aptitud para realizar cuantos esfuerzos demande dicha gestión para llegar a alcanzar las metas propuestas.

V. Autodisciplina, entendida como dominio de sí mismo, controlando las propias tendencias y apetencias, para seguir rectamente la línea trazada al asumir el cargo público, en servicio al pueblo. El político no puede dejarse dominar por sus inclinaciones naturales, pues, en otro caso, sería presa fácil de las ambiciones y de los egoísmos de los demás. Si él es el primero que se respeta, logrará que sus convecinos le respeten también.

VI. Creatividad, considerada como la capacidad para concebir obras y servicios que atiendan y satisfagan las necesidades-comunitarias de la población municipal. Los políticos requieren mucha imaginación para poder resolver los múltiples problemas con los que se tendrán que enfrentar cotidianamente. Imaginación que no estriba en ignorar lo ya existente y en crear en su lugar cosas nuevas; consiste en aprovechar, mejorándolo, lo existente; en continuarlo, en perfeccionarlo $y$, excepcionalmente, en cambiarlo por completo. La creatividad, no hay que olvidarlo, no es destrucción, es creación y es utilización de lo existente en la forma más conveniente a las necesidades populares.

VII. Factibilidad, que implica acometer en cada momento únicamente lo que sea posible realizar, en base a los recursos con que se cuenta; que entraña actuar racionalmente y no de forma emptiva o pasional; que supone actuar de modo creativo y de acuerdo con las normas del ordenamiento jurídico vigente, y que significa, por último, utilizar al máximo dichos recursos, aprovechando las posibilidades que brinden las circunstancias de cada instante. La factibilidad, podríamos decir, en fin, que es el realismo, el sentido común y la oportunidad que deben inspirar la actuación eficaz del político.

VIII. Cooperación, como última nota, entendida tanto como interacción solidaria con los restantes miembros de la Corporación municipal, como con las Asociaciones de Vecinos y con las demás organizaciones de carácter comunitario; como identificación con las metas municipales y con los intereses del pueblo, a los que representa y a los que tiene que defender.

En conclusión, si los políticos municipales, al igual que los deportistas, pudiesen ser definidos siempre por estas notas $-\mathrm{y}$ pen- 
samos que en muchos casos así es-, resultaría que su actuación pública sería congruente con los programas defendidos en la campaña electoral. Lo que significaría que habría concordancia entre lo que prometieron que harian si accedían al Poder y lo que hacen al ocupar y ejercer éste, con lo cual no se podría decir de ellos lo que manifestó John MASEFIELD:

Había tres hombres

que iban por el camino:

el hombre que los demás veían,

el hombre que era en realidad

y el hombre que deseaba ser. 